\title{
The roles of connective tissue growth factor in the development of anastomotic esophageal strictures
}

\author{
Haibin Zhao, Lingna Zhao, Zhihua Zhou, Yaoyi Wu
}

Department of Pathology, the $101^{\text {st }}$ Hospital of Chinese People's Liberation Army, Wuxi, Jiangsu Province, China

Submitted: 16 April 2013

Accepted: 22 August 2013

Arch Med Sci 2015; 11, 4: 770-778

DOI: 10.5114/aoms.2015.48147

Copyright $\odot 2015$ Termedia \& Banach

\section{Abstract}

Introduction: The aim of this study was to investigate the roles of connective tissue growth factor (CTGF) in the development of anastomotic strictures after surgical repair of the esophagus.

Material and methods: Tissues collected from the patients were divided into three groups based on the results of endoscopy and clinical grading. Patients without dysphagia after esophagectomy were used as the control population. The protein levels of CTGF, TGF- $\beta 1$, Smad2, and Smad4 were determined by immunohistochemistry (IHC) and western blot analyses, while the mRNA levels of the two growth factors were evaluated by real-time polymerase chain reaction.

Results: Compared with the control group, significantly increased $(p<0.01)$ levels of CTGF and TGF- $\beta 1$ protein were observed in the anastomotic stenosis (AS) group, and levels of the two proteins detected by the IHC and western blot analyses were also significantly increased with the increasing severity of stenosis $(p<0.05)$. The mRNA levels of CTGF and TGF- $\beta 1$ in the tissues collected from the patients with stenosis were significantly up-regulated $(p<0.05)$ as compared with those from the control group. In addition, the levels of Smad2 and Smad4 protein were also significantly increased $(p<0.05)$ with the increasing severity of stenosis, and the protein levels were positively correlated with the levels of CTGF $(r=0.59, p<0.05)$ and TGF- $\beta 1(r=0.63, p<0.05)$.

Conclusions: Inhibition of CTGF protein or mRNA expression may be a distinctive and effective therapy for the treatment of postoperative anastomotic strictures.

Key words: anastomotic strictures, connective tissue growth factor, esophageal cancer, transforming biochemical factors, surgical repair of the esophagus.

\section{Introduction}

Anastomotic stricture (AS) is a well-recognized postsurgical complication of the esophagus and has been reported to occur in approximately $10 \%$ of patients with surgically treated esophageal cancer [1]. In recent years, the occurrence of anastomotic strictures has increased in prevalence due to the growing usage of the stapler for the surgical procedure. The factors reported to be associated with the development of AS included long-term inflammation, edema, scar hyperplasia, and improper anastomosis, while stenosis is caused by the concentric contraction of the anastomotic ring scar [2]. Currently, local balloon dilation, stenting,

\author{
Corresponding author: \\ Lingna Zhao \\ Department of Pathology \\ $101^{\text {st }}$ Hospital of Chinese \\ People's Liberation Army \\ No. 101 North Xingyuan Road \\ Wuxi 214044, Jiangsu \\ Province, China \\ Phone: +86051085142282 \\ E-mail: \\ zhlnzhao353@hotmail.com
}


and high-frequency electric knife resection are commonly used for treatment of strictures. Since these treatments can only be employed to treat strictures after they have developed, the treatment has limited success. Therefore, to develop an effective treatment strategy that inhibits stricture formation, investigation of the molecular mechanisms involved in formation of anastomotic strictures after esophago-gastrostomy was urgently needed.

There was no consensus about the mechanisms of AS formation. In this study, we tried to assess the roles of connective tissue growth factor (CTGF) in the development of AS. The CTGF, a member of the CCN family, has been identified as an essential mediator of fibrosis maintenance in various pathological conditions [3]. In human renal tubular epithelial cells, CTGF expression inhibited by genistein may help genistein anti-fibrogenic effects [4]. The CCN family members are always induced by growth factors and cytokines such as transforming growth factor (TGF- $\beta$ ) and endothelin 1 and cellular stress such as hypoxia, and are over-expressed in pathological conditions that affect connective tissues, including scarring, fibrosis and cancer [5]. Various pathological stresses can induce CTGF expression, including TGF- $\beta$ [6]. It is reported that TGF- $\beta$ is involved in the positive feedback regulation during Treg differentiation and functions in immunosuppression [7]. The TGF- $\beta$ signaling pathway is involved in carcinogenesis, and alteration of TGF- $\beta$ receptors may be responsible for the development of human cancers [8]. On one hand, a molecular interaction between TGF- $\beta$ and CTGF enhances binding of TGF- $\beta$ to its receptors [9], and on the other hand, the TGF- $\beta$ signaling pathway promotes CTGF transcription through two specific DNA sequences located in the CTGF promoter: the Smad consensus binding site and the TGF- $\beta$ RE/BCE- 1 binding site $[6,10]$. Understanding the cooperation between TGF- $\beta$ and CTGF may therefore be critical to our overall understanding of the AS formation

In the present study, we investigated signaling pathways involved in TGF- $\beta$-induced CTGF transactivation and mainly focused on Smad2 and 4. We tried to identify some important factors associated with the development of AS, and to study the roles of the CTGF pathway in AS formation after surgical repair of the esophagus.

\section{Material and methods}

\section{Study population}

Between January 2004 and December 2011, 3 male and 10 female patients who had undergone esophagectomy and with recurrent dysphagia and benign anastomotic strictures at 101 Hospital of People's Liberation Army were enrolled in the study. The average age of the subjects was 52 $(52 \pm 17)$ years. The severity of dysphagia was assessed by using Stooler's score: grade 1, able to eat soft food; grade 2, able to eat only a semi-liquid diet; grade 3, able to eat only a liquid diet; grade 4 , unable to eat food or swallow saliva. In addition, 4 patients without dysphagia after esophagectomy were used as the control group. The basic characteristic of the study population are shown in Table I.

\section{Material and reagents}

TRIzol RNA isolation reagent and the All-inOne RT-PCR Detection Kits were obtained from Invitrogen Life Technologies (Carlsbad, CA). All the monoclonal antibodies used in this study were purchased from Santa Cruz Biotechnology (Santa Cruz, CA). The Masson's trichrome stain kit, SABC kit, TGF- $\beta 1$ Fluorescence In Situ Hybridization Assay (FISH) kit, and CTGF FISH kit were obtained from Keygen Biotech. Co. Ltd. (Nanjing, China).

\section{Tissue collection}

Informed consent was obtained from all patients before enrolling them in this study. Conventional detection of the degree and properties of strictures was performed by using barium esophagography on esophagogastric anastomotic wounds. Tissue specimens, 3-4 in number and about the size of a grain of rice, were collected from the various anastomotic stricture areas, using biopsy forceps that were introduced through the sheath. All the specimens were fixed with $40 \mathrm{~g} / \mathrm{l}$ neutral buffered formalin. Then, the samples were conventionally dehydrated and embed-

Table I. Basic characteristics of the study population

\begin{tabular}{|lccc|}
\hline Group & Number & Grade & Stricture diameter [cm] \\
\hline Mild stenosis group & 9 & $1-2$ & $>5$ \\
\hline Moderate stenosis group & 8 & 3 & 3 to 5 \\
\hline Severe stenosis group & 6 & 4 & $<2$ \\
\hline Control group & 4 & - & - \\
\hline -Without dysphagia after esophagectomy. - With normal anastomotic stoma & & \\
\hline
\end{tabular}


ded into paraffin. Simultaneously, a part of each sample was snap-frozen and stored in liquid nitrogen for subsequent quantitative real-time polymerase chain reaction (RT-PCR) analysis.

\section{Hematoxylin and eosin $(\mathrm{H}+\mathrm{E})$ staining and Masson's trichrome staining}

The paraffin-embedded samples were mounted on coated slides, and after removing the paraffin, the slides were stained with Sirius red in saturated picric acid for $1 \mathrm{~h}$ at room temperature. After washing the slides with running tap water, hematoxylin was used to counterstain the nucleus for 1 min, followed by dehydration with $95 \%$ alcohol, dimethylbenzene transparency, and gum mounting. Stained tissue sections were observed with an optical microscope. Masson's trichrome stains were used for determination of collagen content and the distribution of collagen fibers in each tissue sample. Stained tissues were observed with an optical microscope.

\section{Immunohistochemistry (IHC)}

Strept Avidin-Biotin Complex (SABC) IHC was used to determine the expression levels of CTGF and TGF- $\beta 1$ protein in tissue samples. Rabbit antibodies against human CTGF and human TGF- $\beta 1$ were diluted $1: 400$ for staining. Dye procedures included heating tissue sections (to achieve antigen recovery), DAB staining, and hematoxylin counterstaining. The yellow or brown staining located in the cytoplasm of the tissue samples represents positive staining. The number, intensity, shape and distribution characteristics of the brown staining were observed with an optical microscope. The color intensity of the tissue was graded as "-” (no color development), "+” (pale brown nucleus and/or cytoplasm), "+++" (deep brown), or "++" (medium brown). Five high-power fields of each specimen tissue randomly selected (at 100x magnification) were observed, and the positively stained cells were counted. Quantitative analysis of the number of positive cells per unit area in each group was performed with a VIDAS image analysis system.

\section{Western blot analysis}

Western blotting was performed to quantitatively assess the levels of TGF- $\beta 1$ and CTGF protein in anastomotic tissues from different groups. The anastomotic tissues were washed twice with cold PBS, cut into pieces, lysed with an appropriate amount of ice cold lysis buffer, and then homogenized in a glass homogenizer. For complete tissue lysis, the homogenized tissue was mixed and chilled on ice for $10 \mathrm{~min}$. After centrifugation, certain volumes of the sample buffer were pipet- ted into a tube. Then the samples were ground and incubated at $95-100^{\circ} \mathrm{C}$ for $5 \mathrm{~min}$, followed by cooling on ice and loading onto sodium dodecyl sulfate polyacrylamide gel. After running, the proteins were transferred onto filter paper membranes, then incubated in a diluted blocking buffer $\left(0.1 \mathrm{ml} / \mathrm{cm}^{2}\right)$, followed by incubation on a shaker overnight at $4^{\circ} \mathrm{C}$ with the appropriate rabbit monoclonal antibody for human Smad2, Smad4, TGF- $\beta 1$, or CTGF. After incubation, the membranes were washed four times for 5 min each with PBST and then were incubated with HRP-conjugated secondary antibodies (HRP-labeled antibody diluted in a blocking buffer for 1-2 $\mathrm{h}$ at room temperature. Finally, the membranes were washed five times for 5 min each with PBST.

\section{RNA extraction and amplification by RT-PCR}

One milliliter of TRIzol reagent was added to the specimen tissues for isolation of total RNA. Nucleic acid purity was determined by measuring $260 \mathrm{~nm} / 280 \mathrm{~nm}$ absorbance ratios. A sample with a ratio of $1.8-2.1$ is considered to be free of protein contaminants. The PCR amplification cycle was set as $95^{\circ} \mathrm{C}$ for $3 \mathrm{~min}$ for initial denaturation, and then 32 cycles were performed under the following conditions: $50 \mathrm{~s}$ at $94^{\circ} \mathrm{C} ; 30 \mathrm{~s}$ at $55^{\circ} \mathrm{C}$; $60 \mathrm{~s}$ at $72^{\circ} \mathrm{C}$, and finally the reaction mixtures were incubated at $72^{\circ} \mathrm{C}$ for $5 \mathrm{~min}$. The primer sequences were as follows: (1) CTGF, forward 5'-GCCATTACAACTGTCCCG-3' and reverse 5'-ACCCTCCCACTGCTCCTA-3'; the expected terminal fragment amplified was about 358 bp in length. (2) NF- $\mathrm{BB}$, forward 5'-CAGAAATACAGCAACAATTCCTGG-3', and reverse 5'-TTGCAGTGTGTTATCCCTGCTGTC-3'; the expected terminal fragment amplified was 186 bp in length. (3) GAD PH (internal control), forward 5'-GGAGCGAGATCCCTCCAAAAT-3', and reverse 5'-GGCTGTTGTCATACTTCTCATGGA-3'. Aliquots $(5 \mu \mathrm{l})$ of the amplification products were analyzed by electrophoresis using 2\% agarose gels containing ethidium bromide $(0.5 \mathrm{mmol} / \mathrm{l})$. The RT-PCR products were visualized by UV transillumination equipment with image scanning software. Data were calculated as the ratio of sample to GAPDH using the UVPro color image analysis system.

\section{Statistical analysis}

The data were analyzed using the SPSS 13.0 software for Windows (SPSS Inc., Chicago, IL, USA). Data are presented as the mean \pm standard deviation $(X \pm s)$. Significant differences between the groups were analyzed by one-way analysis of variance (ANOVA). The bivariate correlation coefficients were evaluated using Pearson's rank test. In all tests, differences were considered statistically significant at $p \leq 0.05$. 


\section{Results}

\section{$\mathrm{H}+\mathrm{E}$ and Masson's trichrome staining of collagen fibers}

HE-stained collagen fibers were observed under a light microscope. Normal collagen fibers were found in the control group (Figure $1 \mathrm{~A}$ ), while, in the AS group, tissue hyperplasia of the collagen fibers and submucosal muscularis were observed
(Figures $1 \mathrm{~B}$ and $1 \mathrm{C}$ ). The Masson's trichrome staining showed that distinct blue collagen fibers and red muscle fibers were observed (Figure 2). Compared with the control group, the deposition of reticular collagen fibers was more abundant in the mesenchyme of the AS group. The vessel wall became obviously thickened, and the narrow lumen was also observed in the AS group (Figures $2 \mathrm{~B}$ and $2 \mathrm{C}$ ).
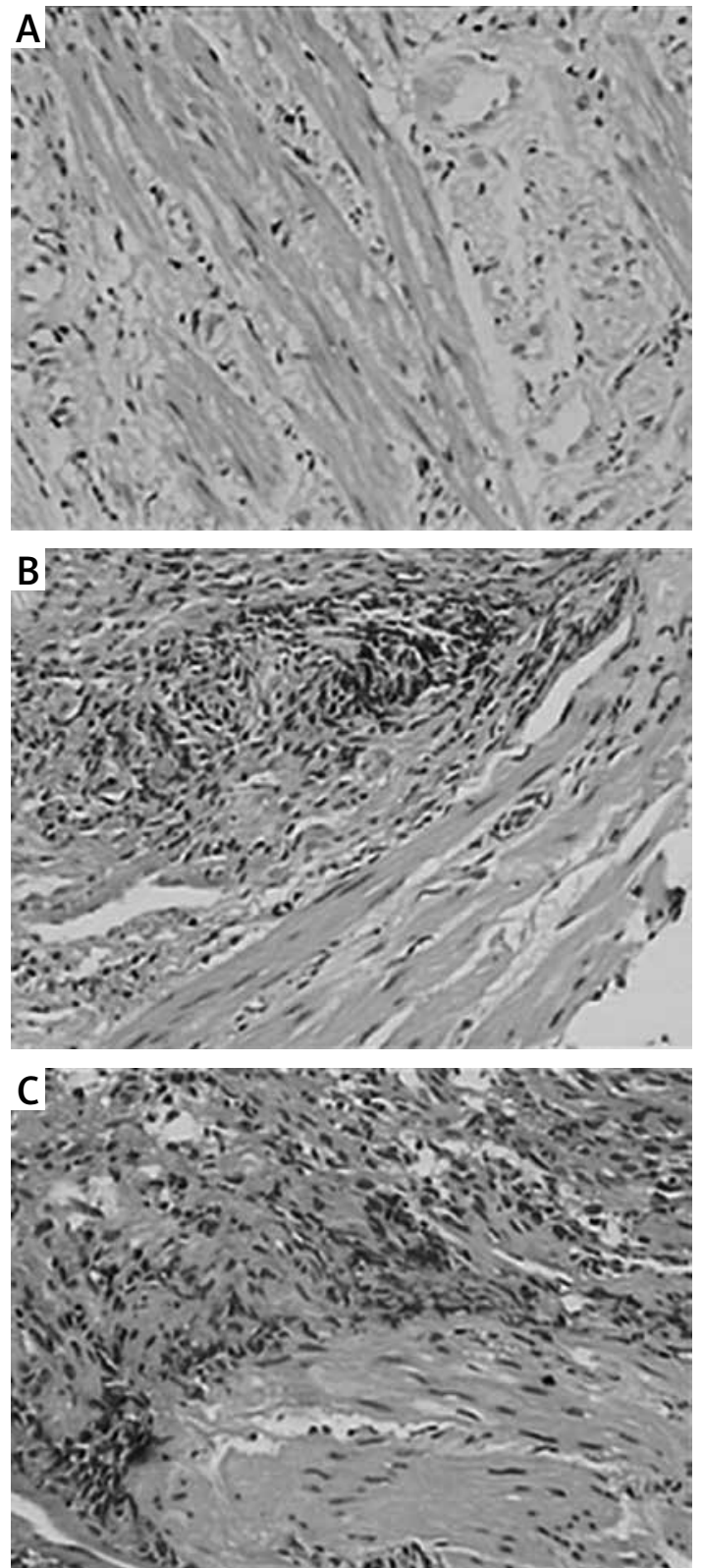

Figure 1. $H+E$ staining of collagen fibers. HEstained collagen fibers were observed under a light microscope (original magnification 200x). Normal collagen fibers were found in the control group, while, in the AS group, tissue hyperplasia of the collagen fibers and submucosal muscularis were observed. A - Control group; B - mild stenosis group; $\mathrm{C}$ - severe stenosis group
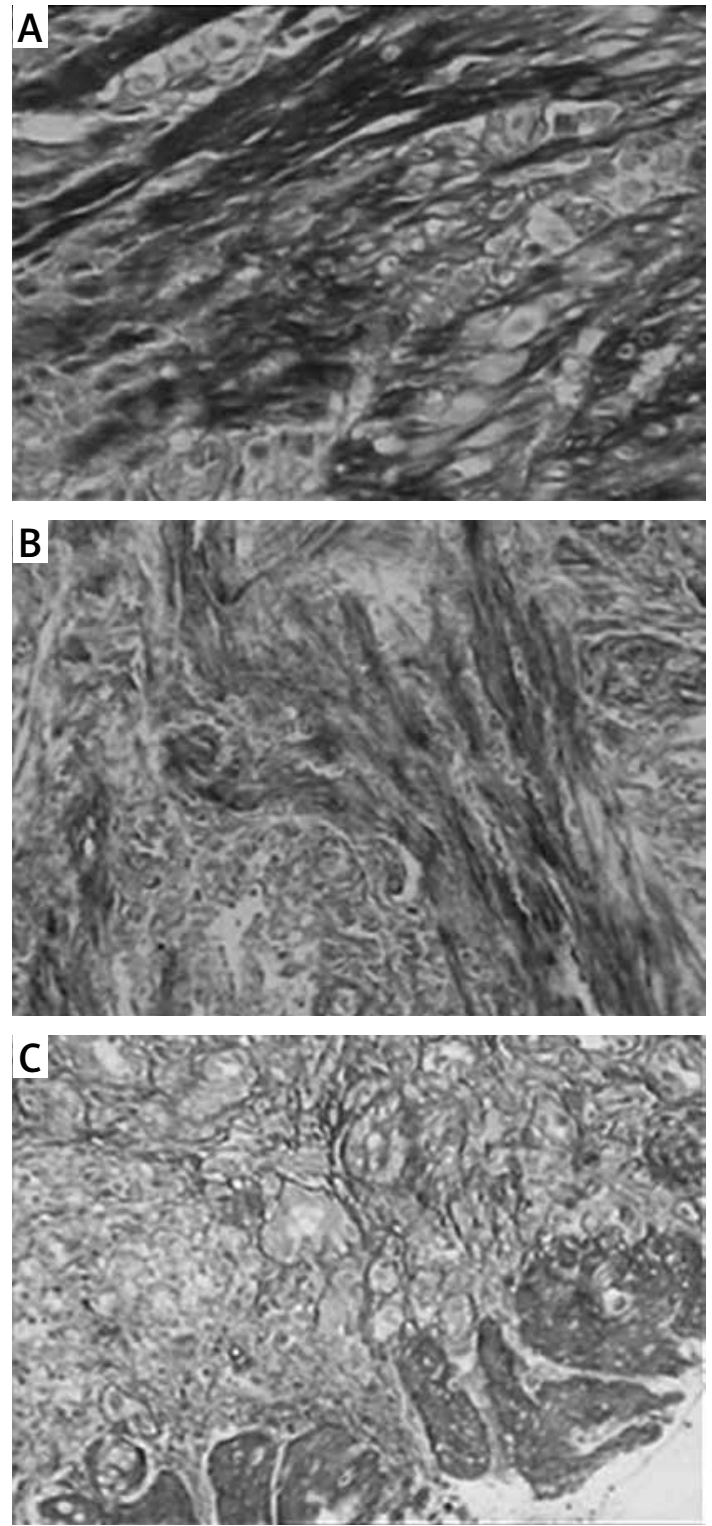

Figure 2. Masson's trichrome staining of collagen fibers (original magnification 200x). The Masson's trichrome staining showed that distinct blue collagen fibers and red muscle fibers were observed. Compared with the control group, the deposition of reticular collagen fibers was more abundant in the mesenchyme of the AS group. The vessel wall became obviously thickened, and a narrow lumen was also observed in the AS group. A - Control group B - mild stenosis group; $\mathbf{C}$ - severe stenosis group 


\section{Levels of TGF- $\beta 1$ protein in the anastomotic tissues}

Levels of TGF- $\beta 1$ protein in tissue samples were determined by SABC IHC. As shown in Figure $3 \mathrm{~A}$ low expression of TGF- $\beta 1$ protein was observed in the control group (Figure $3 \mathrm{~A}$ ), while, in the AS
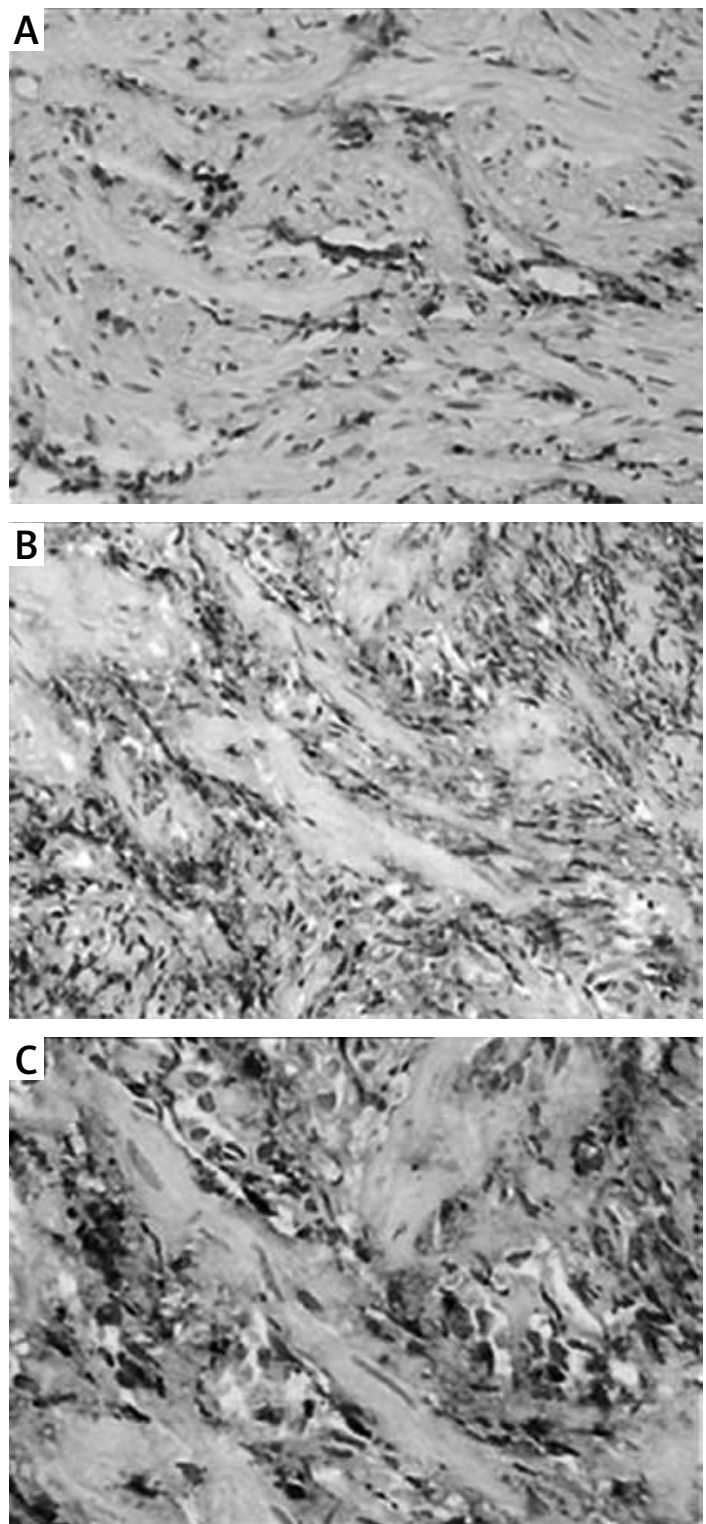

Figure 3. Levels of TGF- $\beta 1$ protein in the anastomotic tissues. Levels of TGF- $\beta 1$ protein in tissue samples was determined by SABC IHC (original magnification 200x). Low expression of TGF- $\beta 1$ protein was observed in the control group, while, in the AS group, levels of TGF- $\beta 1$ protein were significantly increased, and the protein levels increased significantly $(p<0.01)$ with the increasing severity of AS. The positive expression of TGF- $\beta 1$ protein in the AS group was indicated by the brown-yellow granules, mostly located in the cytoplasm of esophageal epithelial cells, endothelial cells, and fibroblasts. A - Control group; $\mathbf{B}$ - mild stenosis group; $\mathbf{C}$ - severe stenosis group group, significant increases $(p<0.05)$ in levels of TGF- $\beta 1$ protein were observed, and the protein levels increased significantly $(p<0.01)$ with the increasing severity of AS (Figures $3 \mathrm{~B}$ and $3 \mathrm{C}$ ). The positive expression of TGF- $\beta 1$ protein in the AS group were indicated by the brown-yel-
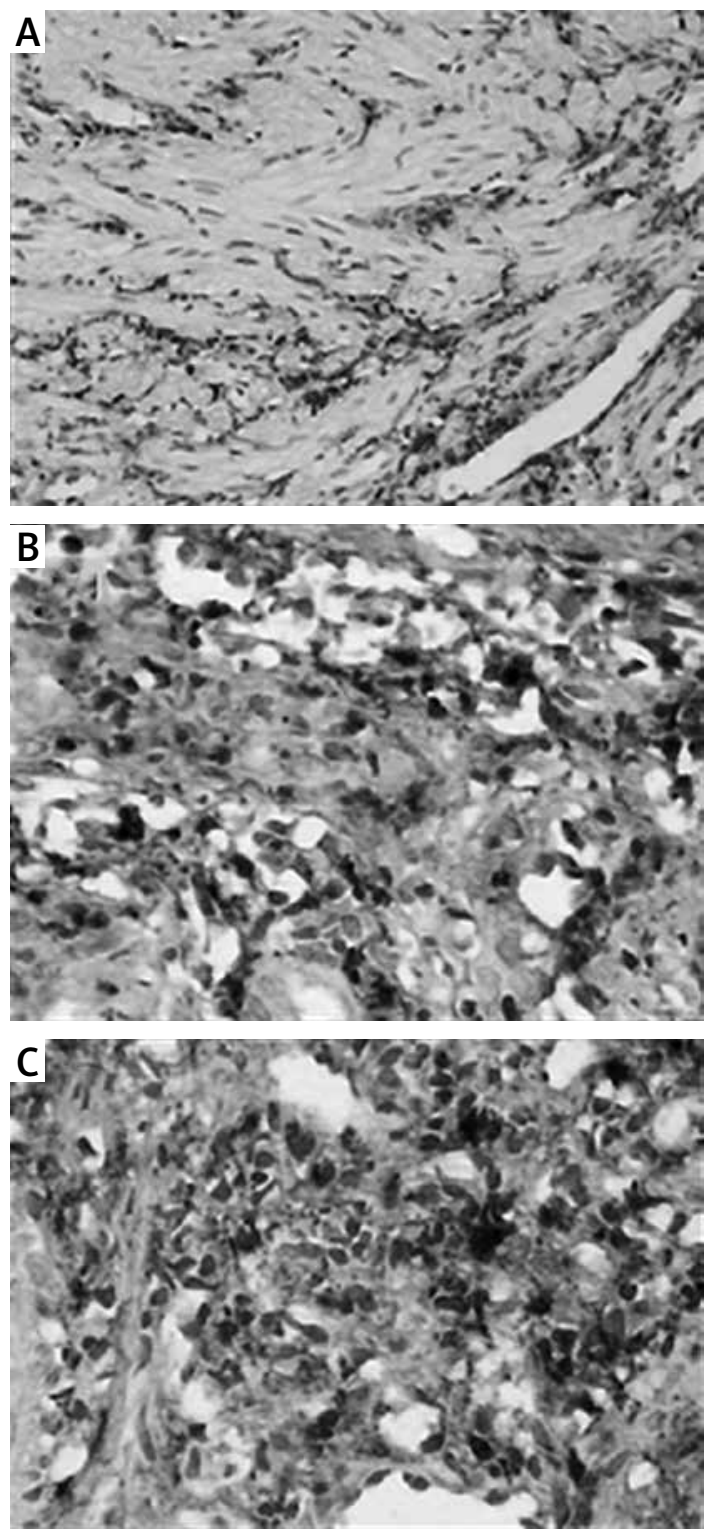

Figure 4. Levels of CTGF protein in the anastomotic tissues. Levels of CTGF protein in tissue samples were determined by SABC IHC (original magnification 200x). Low expression of CTGF protein was observed in the cytoplasm of fibroblasts in the control group, while, in the AS group, significant increases $(p<0.05)$ in levels of CTGF protein were observed in the cytoplasm of fibroblasts, and the fibroblasts were disorganized, showing loss of polarity and strong staining. Compared with the control group, significant increases in the CTGF protein expression were observed in the AS group. The CTGF protein levels increased significantly $(p<0.01)$ with the increasing severity of AS. The positive expression of CTGF protein in the AS group was indicated by the brown-yellow granules. A - Control group; B - mild stenosis group; $\mathbf{C}$ - severe stenosis group 
low granules, mostly located in the cytoplasm of esophageal epithelial cells, endothelial cells, and fibroblasts (Figures $3 \mathrm{~B}$ and $3 \mathrm{C}$ ).

\section{Levels of CTGF protein in the anastomotic tissues}

Levels of CTGF protein in tissue samples were determined by SABC IHC. As shown in Figure $4 \mathrm{~A}$, low expression of CTGF protein was observed in the cytoplasm of fibroblasts in the control group (Figure 4 A), while, in the AS group, significant increases $(p<0.05)$ in levels of CTGF protein were observed in the cytoplasm of fibroblasts (Figures $4 \mathrm{~B}$ and $4 \mathrm{C})$, and the fibroblasts were disorganized, showing loss of polarity and strong staining. Compared with the control group, significant increases in the CTGF protein expression were observed in the AS group $(p<0.05)$. The CTGF protein levels increased significantly $(p<0.01)$ with the increasing severity of AS.

\section{Levels of TGF- $\beta 1$ and CTGF mRNA \\ in the anastomotic tissues}

The mRNA levels of TGF- $\beta 1$ and CTGF were determined by RT-PCR analysis. The mRNA levels detected by RT-PCR are shown in Figure 5 and levels of TGF- $\beta 1$ and CTGF mRNA were determined by densitometric analysis (Figure 6). As shown in Figures 5 and 6 , levels of TGF- $\beta 1$ and CTGF mRNA in the AS group were significantly up-regulated $(p<0.05)$ compared with the control group, and the mRNA levels significantly increased $(p<0.05)$ with the increasing severity of AS.

\section{Protein expression of TGF- $\beta 1 / \mathrm{Smad} / \mathrm{CTGF}$ examined by western blot analysis}

Levels of CTGF, TGF- $\beta 1$, p-Smad- 2 , and Smad4 were evaluated by western blotting analysis. The CTGF, TGF- $\beta 1$, p-Smad- 2 , and Smad4 protein expression were normalized to the housekeeping gene actin. As shown in Figures 7 and 8, significant up-regulation of TGF- $\beta 1$ and CTGF protein expression was observed as compared with that of the control group ( $p<0.05)$ (Figures 7 and 8). The protein levels of TGF- $\beta 1$ and CTGF increased significantly with the severity of strictures in different groups $(p<0.05)$. Significant increases in levels of Smad 2 and Smad 4 protein were also found in the AS group $(p<0.05)$, which were positively correlated with the expression of TGF- $\beta 1$ $(r=0.59, p<0.05)$ and CTGF $(r=0.63, p<0.05)$, respectively.

\section{Discussion}

An anastomotic stricture (AS) is a type of pathological scar healing process of surgical incisions. The pathological mechanisms of AS mainly include the excessive proliferation of fibroblast-based cell components and the excessive deposition of collagen-based extracellular matrix. Although the pathogenesis of strictures is not clearly understood, the cytokines released by the platelets and various stromal cells are reported to play a key role in the occurrence, development, as well as the outcome of the anastomotic healing process [11].

The TGF- $\beta 1$ is a multifunctional cytokine that participates in the regulation of cell proliferation,

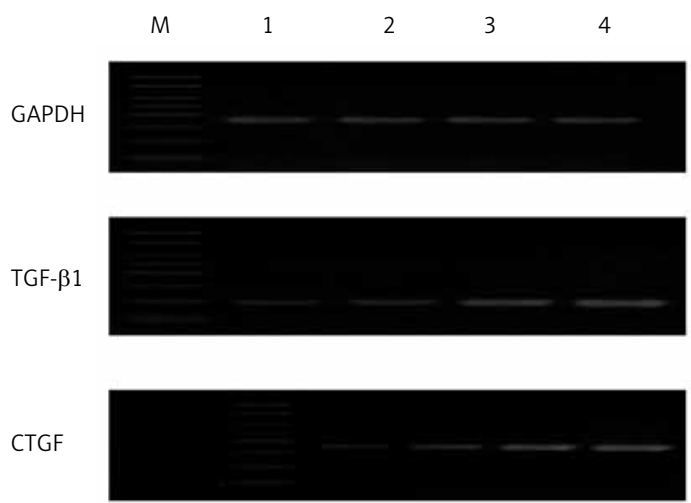

Figure 5. MRNA levels of TGF- $\beta 1$ and CTGF detected by RT-PCR. Levels of TGF- $\beta 1$ and CTGF mRNA in the AS group were up-regulated compared with the control group, and the mRNA levels increased with the increasing severity of AS. $M$ - marker; 1 - control group; 2 - mild stenosis group; 3 - moderate stenosis group; 4 - severe stenosis group

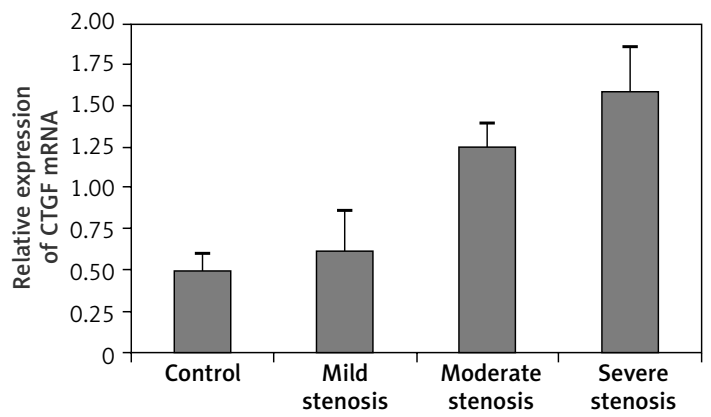

Figure 6. Relative expression of TGF- $\beta 1$ and CTGF mRNA compared with the GAPDH housekeeping gene. The anastomotic strictures group showed significant upregulation in relative mRNA levels of TGF- $\beta 1$ and CTGF as compared with those of the control group $(p<0.05)$. The mRNA levels of TGF- $\beta 1$ and CTGF increased with the severity of strictures $(p<0.05)$ 
Actin

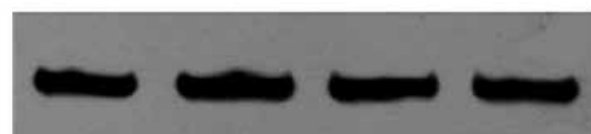

CTGF

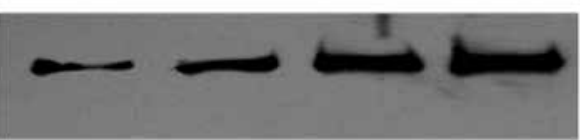

p-Smad2

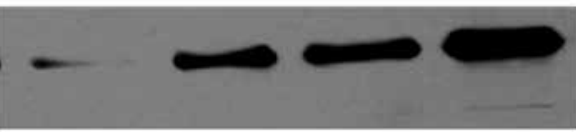

Smad4

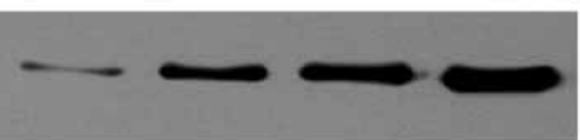

TGF- $\beta 1$

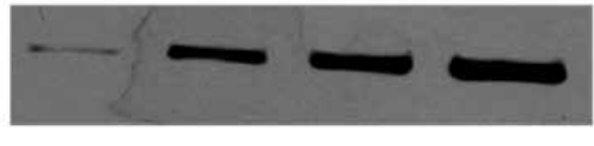

Figure 7. Levels of CTGF, TGF- $\beta 1$, $p-$ Smad-2, and Smad4 protein were evaluated by western blotting analysis. Compared with the control group, levels of CTGF, TGF- $\beta 1$, p-Smad-2, and Smad4 protein were up-regulated. The protein levels of TGF- $\beta 1$ and CTGF increased with the severity of strictures in different groups. 1 - Control group; 2 - mild stenosis group; 3 - moderate stenosis group; 4 - severe stenosis group
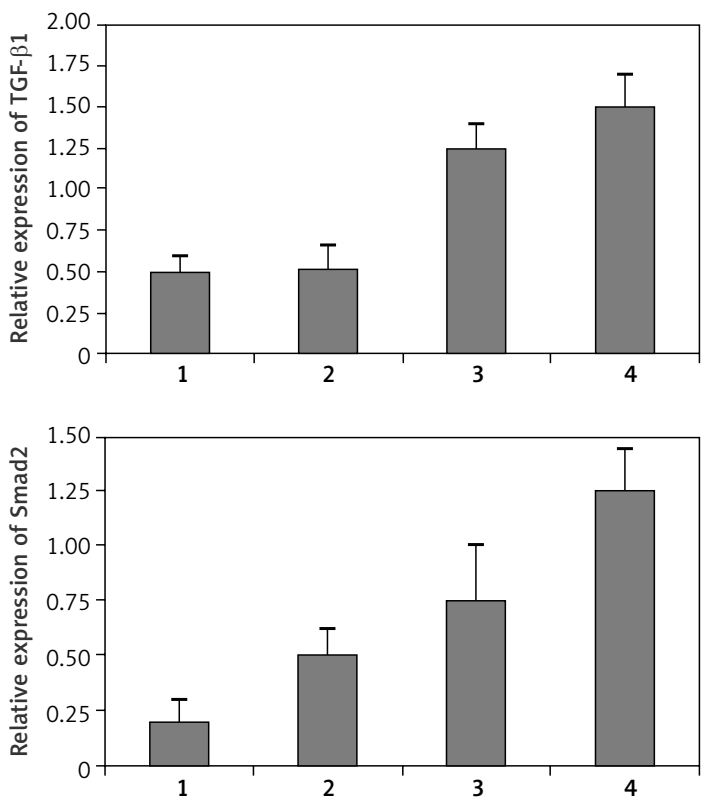

Figure 8. Relative expression of CTGF, TGF- $\beta 1$, p-Smad-2, and Smad4 protein. The CTGF, TGF- $\beta 1$, p-Smad- 2 , and Smad4 protein expression was normalized to the housekeeping gene actin. Compared with the control group, levels of CTGF, TGF- $\beta 1$, $p$-Smad-2, and Smad4 protein were significantly up-regulated $(p<0.05)$. The protein levels of TGF- $\beta 1$ and CTGF increased significantly with the severity of strictures in different groups $(p<0.05)$. Levels of Smad and Smad4 protein were positively correlated with the expression of TGF- $\beta 1(r=0.59, p<0.05)$ and CTGF $(r=0.63, p<0.05)$, respectively. 1 - Control group; 2 - mild stenosis group; 3 - moderate stenosis group; 4 - severe stenosis group
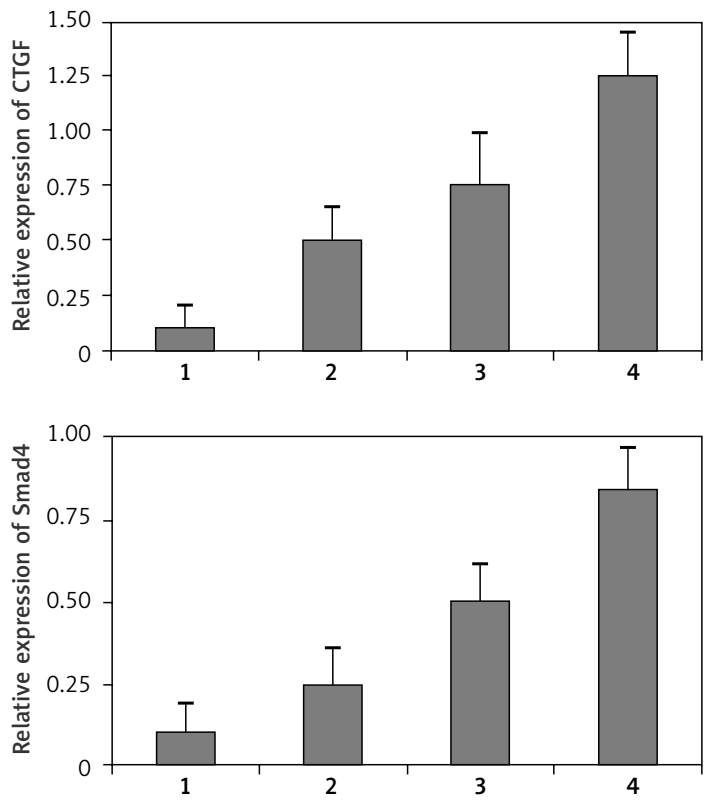

cell differentiation, and extracellular matrix expression [12-14]. It has been reported that TGF- $\beta 1$ may play an important role in the development of fibrous hyperplasia $[15,16]$. It is one of the most important cytokines involved in fibrosis. Overexpression of TGF- $\beta 1$ protein can be detected in the granulated tissues, fibroblasts, macrophages, and endothelial cells of the normal esophageal tissue $[17,18]$. The TGF- $\beta 1$ could stimulate extracellular matrix (ECM) generation at the early stages of wound healing by inhibiting proteases and matrix enzyme activity, and promoting ECM deposition [19]. Overexpression or intermittent high expression of TGF- $\beta 1$ can lead to metabolism regulation disorders of the inflammatory cells, repair cells, and collagen, excessive fibroblast proliferation, and excessive synthesis of procollagen I, which eventually result in hyperplasia of local tissue fibers and luminal strictures [20].

In the present study, low or undetectable expression of TGF- $\beta 1$ protein and mRNA was observed in the control group. Compared with the control group, the levels of TGF- $\beta 1$ protein and mRNA in the anastomotic strictures (AS) group were significantly increased. In addition, TGF- $\beta 1$ protein expression increased with the severity of strictures, suggesting that suppression of TGF- $\beta 1$ expression and activity may help prevent or reduce the occurrence of postoperative anastomotic scar hyperplasia and luminal stenosis. However, due to 
the expression of TGF- $\beta 1$ in a wide variety of cells and its complex biological effects, the impact of blocking TGF- $\beta 1$ expression will not be limited to the connective tissue. Blocking of TGF- $\beta 1$ expression or its activity may also lead to development of autoimmune diseases or even cancer. Studies of TGF- $\beta 1$ knockout mouse models have shown that due to loss of inflammation inhibition, mice die of a severe systemic inflammatory response soon after birth [6]. Therefore, effector molecules that are downstream of TGF- $\beta 1$ may serve as better therapeutic targets.

The CTGF is a newly discovered cysteine-rich polypeptide with multiple biological functions [21]. It is commonly expressed in a variety of human tissues and organs, and it has been reported that CTGF can promote mitosis and collagen synthesis, as well as cell proliferation and ECM synthesis $[22,23]$. Both in vivo and in vitro results showed that TGF- $\beta 1$ can specifically induce the expression of CTGF in the process of cicatrization [24]. As a specific downstream effector-mediator of TGF$\beta 1$-induced fibrosis, CTGF can promote: (1) in vitro connective tissue proliferation; (2) proliferation and hypertrophy of smooth muscle cells and fibroblasts; (3) ECM synthesis; (4) in vivo granulation of tissue and fibrosis; and (5) vascular formation $[25,26]$. Thus, CTGF may play an important role in the formation and maintenance of postoperative anastomotic fiber hyperplasia.

Overexpressed CTGF in the fibroblasts will result in the up-regulation of ECM protein, including type I collagen and fibronectin [27]. The increase in the activity of matrix metalloproteinases could simultaneously inhibit the degradation of ECM protein [28]. Our results showed that the collagen deposition was markedly increased in the tissue samples from the AS group. Douthwaite et al. found that drugs such as cyclophosphamide, prostaglandin E2 (PGE2), and Iloilo prostaglandin (lloprost) can effectively reduce the induction of CTGF via the TGF- $\beta 1$-dependent signal pathway in normal rat kidney fibroblasts [29]. Haydont et al. found that statins can reduce the basal expression of CTGF and interfere with lysophosphatidic acid (LPA)-induced and TGF- $\beta$-induced CTGF expression [30]. However, the mechanism of TGF$\beta 1$-induced CTGF expression is not completely understood. Many studies have shown that the Smads family may play a key role in the process of conducting the TGF- $\beta$ signals from the cell surface receptor to the nucleus [27]. The Smad family, including at least 9 Smad proteins, named Smad $1-9$, could interact with the various TGF- $\beta$ family members [31]. For instance, Smad 2 is a kind of receptor-activated protein that is activated by the active form of TGF- $\beta$ [32], while Smad4 is a commonly needed mediator in various TGF- $\beta$ family signal conduction pathways [33]. In the present study, we tried to figure out the exact mechanism of TGF- $\beta$-induced CTGF expression.

In conclusion, in this study, compared with the control group, levels of TGF- $\beta 1$, Smad2, Smad4, and CTGF were significantly up-regulated in the AS group $(p<0.05)$. Increasing with the degree of pathological fibrosis formation, the CTGF expression seems to exhibit an extremely close relationship with the development of fibrous tissue proliferation. Correlation analyses revealed that the protein levels of Smad2 and Smad4 were positively correlated with the expression of TGF- $\beta 1$ $(r=0.59, p<0.05)$ and CTGF $(r=0.63, p<0.05)$, respectively. Thus, our results demonstrated that the TGF- $\beta 1 /$ Smad/CTGF pathway is activated in benign anastomotic stricture formation processes and may play an important role in cicatrization. The Smads signaling pathway may be involved in TGF- $\beta 1-C T G F$ induction. Therefore, CTGF can be considered to be a new target for the treatment of the cicatrization process.

Although CTGF-targeted treatment for the tissue stricture formation process has not yet been reported, our research provides a theoretical basis for further exploration of new therapies for AS. In the process of wound repair or fibrosis, CTGF is one of the most important cytokines that selectively interferes with the formation of connective tissue. Inhibition of CTGF expression may prove to be a specific and effective therapy for the treatment of postoperative anastomotic stricture.

\section{Conflict of interest}

The authors declare no conflict of interest.

\section{References}

1. Schuchert MJ, Luketich JD, Landreneau RJ. Management of esophageal cancer. Curr Probl Surg 2010; 47: 845-946.

2. Cassivi SD. Leaks, strictures, and necrosis: a review of anastomotic complications following esophagectomy. Semin Thorac Cardiovasc Surg 2004; 16: 124-32.

3. Yeger H, Perbal B. The CCN family of genes: a perspective on CCN biology and therapeutic potential. J Cell Commun Signal 2007; 1: 159-64.

4. Guo YS, Zhang AP, Ding YH, Wang YX, Yuan WJ. Genistein ameliorates parathyroid hormone-induced epithelialto-mesenchymal transition and inhibits expression of connective tissue growth factor in human renal proximal tubular cells. Arch Med Sci 2013; 9: 724-30.

5. Leask A, Abraham DJ. All in the CCN family: essential matricellular signaling modulators emerge from the bunker. J Cell Sci 2006; 119: 4803-10.

6. Blom IE, Goldschmeding R, Leask A. Gene regulation of connective tissue growth factor: new targets for antifibrotic therapy? Matrix Biol 2002; 21: 473-82.

7. Li S, Li Y, Qu X, Liu XL, Liang J. Detection and significance of TregFoxP3+ and Th17 cells in peripheral blood of nonsmall cell lung cancer patients. Arch Med Sci 2014; 10: 232-9. 
8. Liu XL, Shan YX, Xue BX. Int7G24A polymorphism (rs334354) and cancer risk. Arch Med Sci 2013; 9: 3-7.

9. Abreu JG, Ketpura NI, Reversade B, De Robertis EM. Connective-tissue growth factor (CTGF) modulates cell signalling by BMP and TGF-beta. Nat Cell Biol 2002; 4: 599-604.

10. Grotendorst GR, Okochi H, Hayashi N. A novel transforming growth factor beta response element controls the expression of the connective tissue growth factor gene. Cell Growth Differ 1996; 7: 469-80.

11. Muehlich S, Schneider N, Hinkmann F, Garlichs CD, Goppelt-Struebe $M$. Induction of connective tissue growth factor (CTGF) in human endothelial cells by lysophosphatidic acid, sphingosine-1-phosphate, and platelets. Atherosclerosis 2004; 175: 261-8.

12. Bujak M, Frangogiannis NG. The role of TGF-beta signaling in myocardial infarction and cardiac remodeling. Cardiovasc Res 2007; 74: 184-95.

13. Kollias HD, McDermott JC. Transforming growth factor-beta and myostatin signaling in skeletal muscle. J Appl Physiol 2008; 104: 579-87.

14. Tanigawa T, Pai R, Arakawa T, Higuchi K, Tarnawski AS TGF-beta signaling pathway: its role in gastrointestinal pathophysiology and modulation of ulcer healing. J Physiol Pharmacol 2005; 56: 3-13.

15. Daniels JT, Schultz GS, Blalock TD, et al. Mediation of transforming growth factor-beta(1)-stimulated matrix contraction by fibroblasts: a role for connective tissue growth factor in contractile scarring. Am J Pathol 2003; 163: 2043-52.

16. Mackinnon AC, Gibbons MA, Farnworth SL, et al. Regulation of transforming growth factor-beta1-driven lung fibrosis by galectin-3. Am J Respir Crit Care Med 2012; 185: 537-46.

17. Natsugoe S, Xiangming C, Matsumoto $M$, et al. Smad4 and transforming growth factor beta 1 expression in patients with squamous cell carcinoma of the esophagus. Clin Cancer Res 2002; 8: 1838-42.

18. Vitsky A, Waire J, Pawliuk R, et al. Homeostatic role of transforming growth factor-beta in the oral cavity and esophagus of mice and its expression by mast cells in these tissues. Am J Pathol 2009; 174: 2137-49.

19. Zhang L, Yang M, Bi N, et al. Association of TGF-betal and XPD polymorphisms with severe acute radiation-induced esophageal toxicity in locally advanced lung cancer patients treated with radiotherapy. Radiother Oncol 2010; 97: 19-25.

20. Li CH, Lee RP, Lin YL, et al. The treatment of propofol induced the TGF-beta1 expression in human endothelial cells to suppress endocytosis activities of monocytes. Cytokine 2010; 52: 203-9.

21. Sonnylal S, Shi-Wen X, Leoni P, et al. Selective expression of connective tissue growth factor in fibroblasts in vivo promotes systemic tissue fibrosis. Arthritis Rheum 2010; 62: 1523-32.

22. Seher A, Nickel J, Mueller TD, et al. Gene expression profiling of connective tissue growth factor (CTGF) stimulated primary human tenon fibroblasts reveals an inflammatory and wound healing response in vitro. $\mathrm{Mol}$ Vis 2011; 17: 53-62.

23. Blom IE, van Dijk AJ, Wieten $L$, et al. In vitro evidence for differential involvement of CTGF, TGFbeta, and PDGF-BB in mesangial response to injury. Nephrol Dial Transplant 2001; 16: 1139-48.

24. Shi-Wen X, Leask A, Abraham D. Regulation and function of connective tissue growth factor/CCN2 in tissue repair, scarring and fibrosis. Cytokine Growth Factor Rev 2008; 19: 133-44
25. Yu J, Prado GN, Schreiber B, Polgar P, Polgar P, Taylor L Role of prostaglandin E(2) EP receptors and cAMP in the expression of connective tissue growth factor. Arch Biochem Biophys 2002; 404: 302-8.

26. Mori $Y$, Hinchcliff $M$, Wu $M$, Warner-Blankenship $M$ Lyons K, Varga J. Connective tissue growth factor/CCN2null mouse embryonic fibroblasts retain intact transforming growth factor-beta responsiveness. Exp Cell Res 2008; 314: 1094-104.

27. Haydont $V$, Mathe $D$, Bourgier $C$, et al. Induction of CTGF by TGF-beta1 in normal and radiation enteritis human smooth muscle cells: Smad/Rho balance and therapeutic perspectives. Radiother Oncol 2005; 76: 219-25.

28. Sang QX, Jin Y, Newcomer RG, et al. Matrix metalloproteinase inhibitors as prospective agents for the prevention and treatment of cardiovascular and neoplastic diseases. Curr Top Med Chem 2006; 6: 289-316.

29. Douthwaite JA. Signals controlling CTGF in scarring. TRENDS in Biotechnology 2001; 19: 126.

30. Haydont V, Bourgier C, Fransois A, et al. 137 Treatment of radiation enteritis with pravastatin: role of the rho pathway on CTGF expression. Radiother Oncol 2006; 78: S45.

31. Piek E, Heldin CH, Ten Dijke P. Specificity, diversity, and regulation in TGF-beta superfamily signaling. FASEB 1999; 13: 2105-24.

32. Wahab NA, Weston BS, Mason RM. Modulation of the TGFbeta/Smad signaling pathway in mesangial cells by CTGF/CCN2. Exp Cell Res 2005; 307: 305-14.

33. Yu F, Chou CW, Chen CC. TNF-alpha suppressed TGFbeta-induced CTGF expression by switching the binding preference of p300 from Smad4 to p65. Cell Signal 2009; 21: 867-72. 